\title{
Visual Tools for a Multiple Cross-reading in the Exhibition Context
}

\author{
Alessandra Bosco ${ }^{1}$, Elena La Maida ${ }^{1}$ and Michele Zannoni ${ }^{1}$ \\ 1 Università degli Studi della Repubblica di San Marino, Dipartimento di Economia, \\ Scienze e Diritto, Repubblica di San Marino \\ \{alessandra.bosco, elena.lamaida, michele.zannoni\}@unirsm.sm
}

\begin{abstract}
As researchers who participate in common studies, we need a tool for reading and understanding collected data in its complexity, for analysing and researching the relationship between records at various levels of information within the database, and for getting them networked. This paper presents our project for a visual tool characterized by an interface based on an interactive system for data visualization, which can be configured as required. Graphs and diagrams become part of the process and tools for verifying and enhancing the state of the research.
\end{abstract}

Keywords: visual interactive tool / data visualization / database interface

\section{Text}

In the research program "Enhancement of the cultural heritage in exhibition and museum contexts through the use of new technologies" which began in September 2016 at the University of San Marino, we worked within a contemporary context that is not still completely historicized and not critically addressed. We collected data from traditional sources such as books and articles in scientific journals, but even in exhibition catalogues, designer websites, online blogs and exclusively oral sources such as interviews. After eight months of work on information gathering and data systematisation - with the aim of defining the advancement and the potential of using new digital technologies in the design of exhibition contexts - we experienced how the data could conceal information rather than reveal it.

Today research programs regardless of the disciplinary field of study, often expect that a few people simultaneously pick up information as they interact with wider resource ecosystems, in which contents are increasingly becoming available by free access [1]. So, day after day, sharing, they receive a large mass of data in which they must orient themselves [2].

The variety of the data, systemized and ordered in structured databases, may be queried and filtered. Generally, the different queries lead to identifying an author, a reference, a place, a date, a project or more elements of the same or different 
typologies. The results are often displayed in textual forms that so not provide any hierarchy or links or even associations among data. In this way, researchers don't have an immediate feedback in reading the queries and find it difficult to manage the complexity of the references they have collected.

As researchers who participate in common studies, we need a tool for reading and understanding the data collected in their complexity, for analysing and researching the relationship between records at various levels of information within the database and getting them networked [3]. The aim was to be able to interrogate the data as a whole, systematically ordered, collected and filtered according to parameters and relationships defined in advance, in order to originate dynamic, generative and immediate reading narrations $[4 ; 5]$.

The research led to the development of a project with an interface based on interactive tools for data visualization, that can be configured as required. Graphs and diagrams become a part of the process and tools for verifying and enhancing the state of the research. Scholars can in fact visualize the data to check the accuracy of the stored information, verify any gaps in the collection of data, but also rely on keywords and parameters to understand the connections between records and visualize various narrations.

Following the preliminary process of data collection, representative of the current state of exhibition design, we proceeded to systematize the results choosing parameters to facilitate both cataloguing and searching inside the database.

The project for the visual tool began by observing a series of case studies in data visualization. We focused on how to display people's networks, how use a timeline to display the relationship between catalogued projects and the technology they used and how to display projects identified by keywords.

The first typology of visualization works on networks between people. (Fig.1)

In our project, nodes and relationships between designers are visualized on an interactive map. Data visualization allows us to connect different generations of designers, identifying pioneers, defining membership groups and their followers making it possible to discover the evolution of the project in this area.

We refer to: Santiago Ortiz in Lostalgic [6] (2012) - a complete representation of the scripts of ABC's television series "LOST" - and in the Twitter Company [7] - a visualization showing one week of conversations on Twitter in 2013 - which uses an articulated and dynamic navigation interface [8]. However, our main focus was on The ImpulsBauhaus [9] by Jens Weber and Andreas Wolter (2009) and the Multitouch installation [10] by the Max Planck Institute (2011); projects in which the relationships between people are visualized on interactive maps, the first developed through the use of fiducial markers [11], the second displayed on a multi-touch installation [12]. 


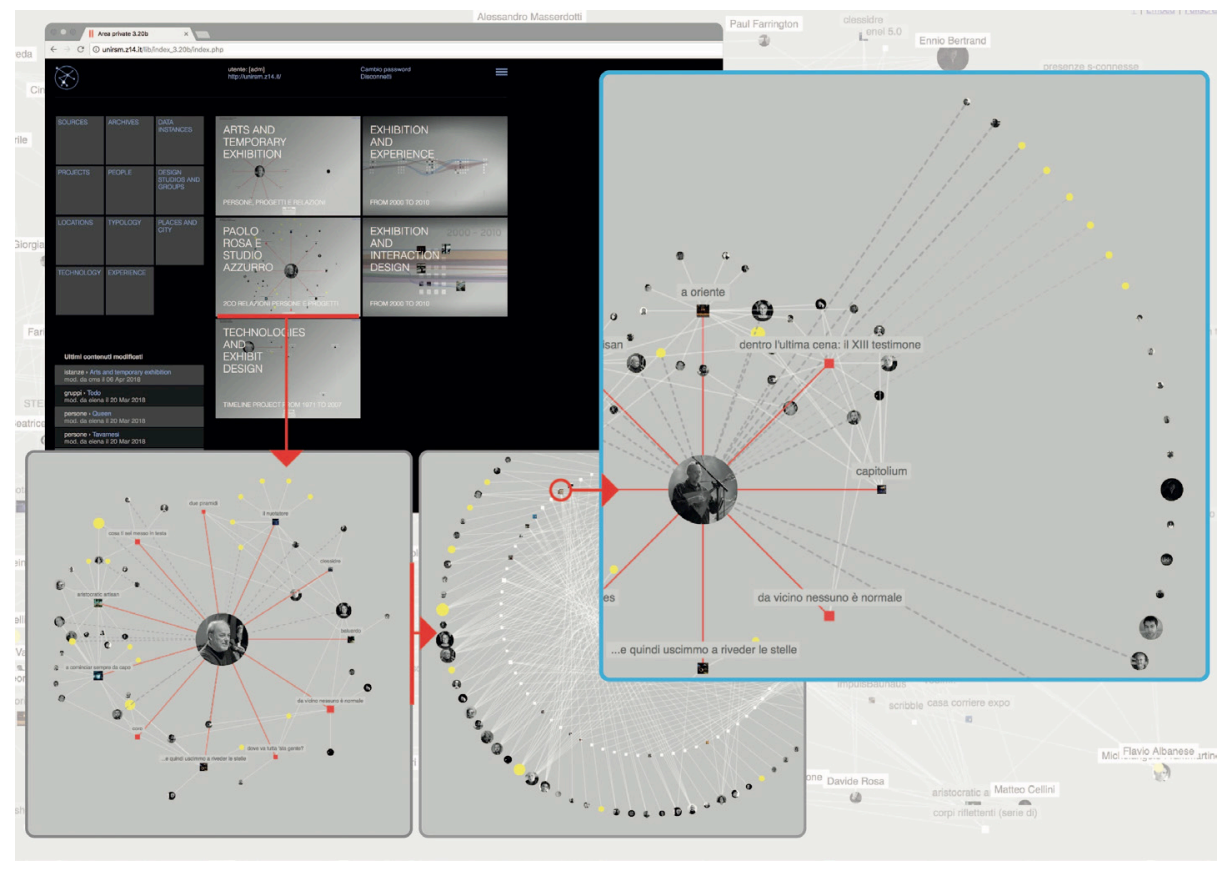

Fig. 1. An example of interactive maps integrated in the designed tool. They visualize nodes and relationships between designers and their common projects.

The second typology analyses data relating to the dimension of time. (Fig.2)

In our project this data visualization displays the relationship between catalogued projects and the technology used to realize them along a timeline. The diagrams with good accessibility and readability show the interactive system that provides the distribution of complex information in a linear development of coloured bands.

We refer to: The MIT Senseable City Lab in Spring spree [13] (2011), which visualizes the financial footprint on a geographic map, underlining consumer behaviour in a defined spatial-temporal range (BBVA bank dataset of transactions) [14]. The Ebb and Flow of Movies: Box Office Receipts 1986 - 2008 [15], by The New York Times group, visualizes Blockbuster's box office revenue and the longevity of bookings from 1986 to 2008 [16; 17]. However, we focused more specifically on The evolution of web [18] designed in 2010-2012 by The Google Research Team, an updated interactive piece based on a static infographic which represented technologies and browsers, illustrating the evolution of the system since the 1990's [19]. And in The Music Timeline [20] by the same group (2014), based on the music library of Google Play Music users, the timeline makes it possible to see how different musical genres grew or shrank in popularity through the years from 1950's to the present [21]. 


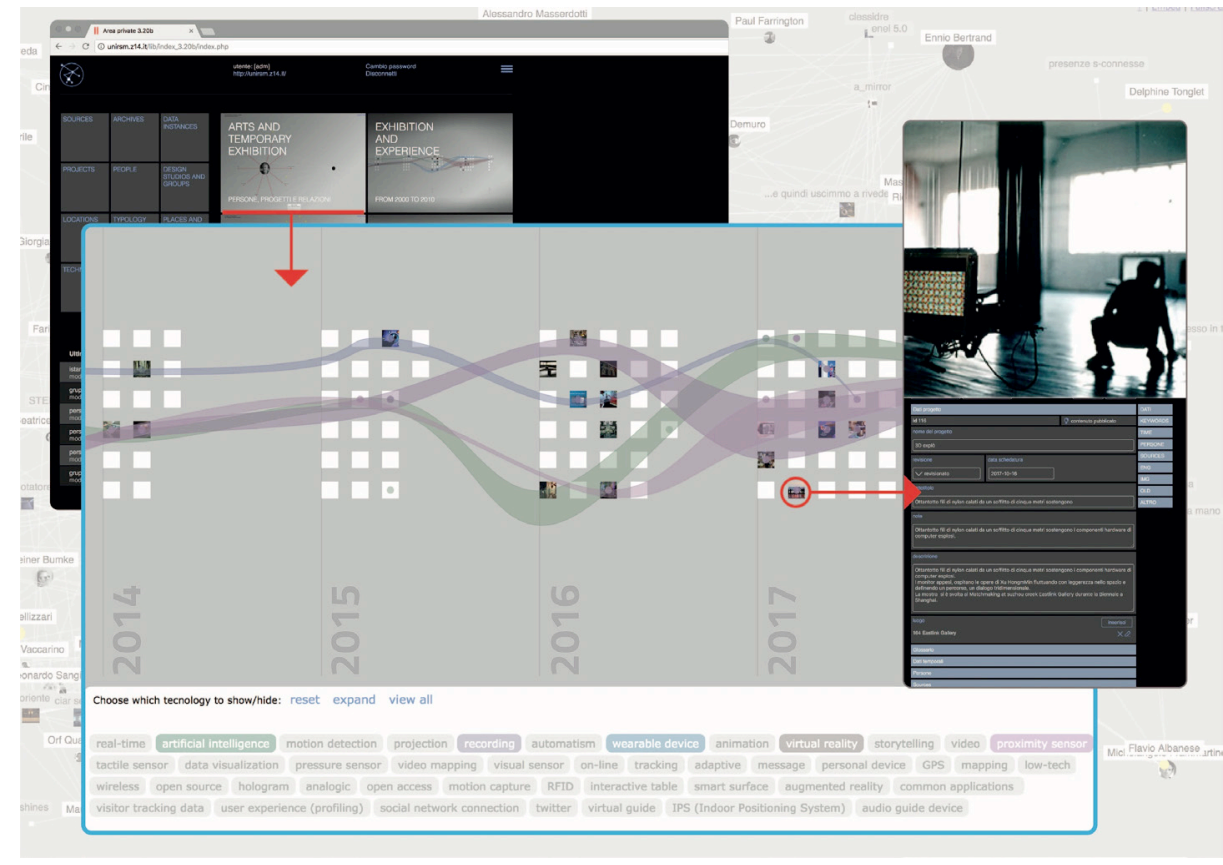

Fig. 2. An example of the visualization which relies on a timeline to display the relationship between catalogued projects and the technology used to realize them.

The third typology investigates relationships between records using keywords, parameters and filters. (Fig.3)

In our project, we explore the reciprocal relationship between the catalogued exhibition projects and the three categories of tags representative of this context: the exhibition typology, the technologies adopted and the variety of the visitor experience. We have provided an interactive network to illustrate the connections between projects through keywords.

We refer to: the website for the exhibition Design and the Elastic Mind [22], by THA Ldt. (2008), which explored the reciprocal relationship between science and design in the contemporary world using new methods of tagging and realizing an efficient contextual browsing of many works [23]. Tags [24], by Google Research Team (2016), that through Machine Learning, using picture recognition, looked at the artworks and generated thousands of tags useful for research [25]. The MIT Senseable City Labs project, Health InfoScape [26] (2011) which analyses data from over 7.2 million anonymized electronic medical records from General Electric's database and creates a disease network to illustrate relationships between different conditions and their effects on health [27]. And How Different Groups Spend Their Day [28], an interactive visualization published in July 2009 by a research group of 
The New York Time journal, which let users explore how different groups in America spend their day $[16 ; 17]$.

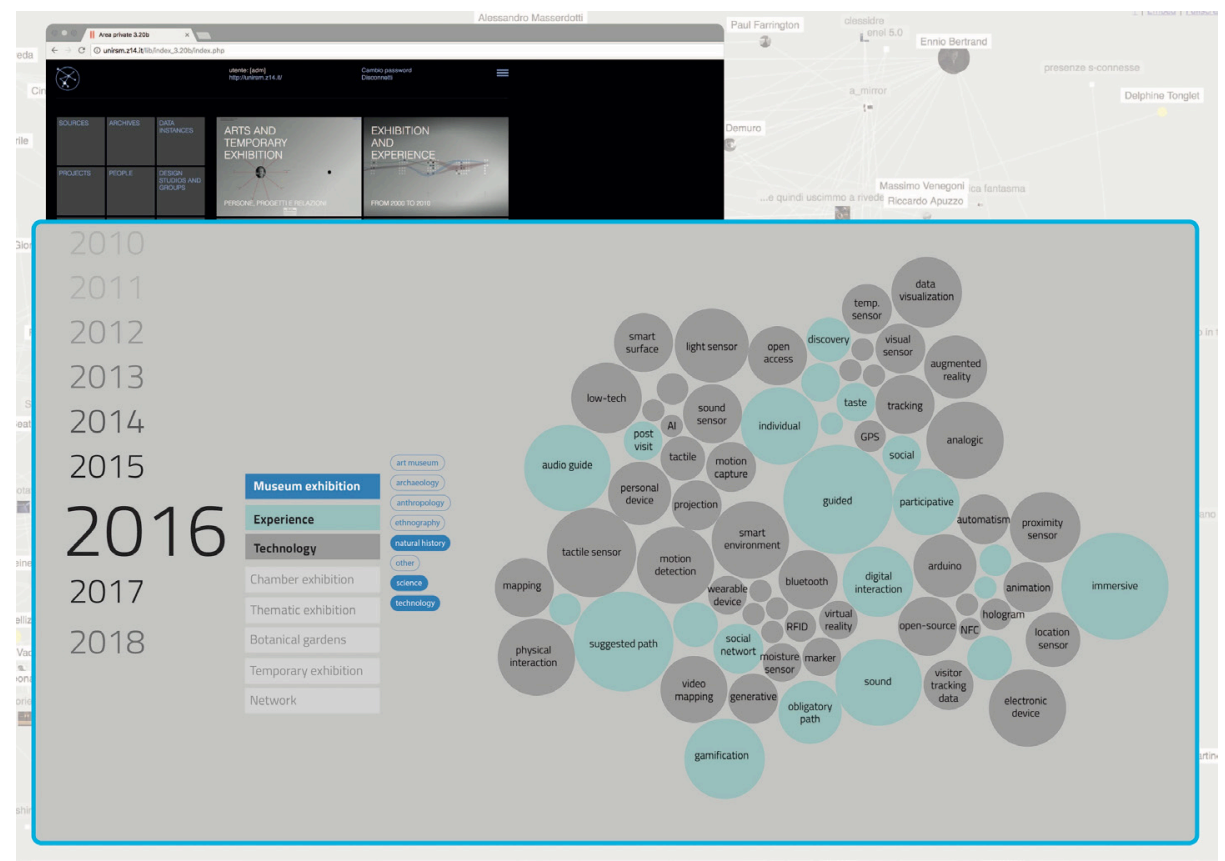

Fig. 3. An interactive visualization example that displays the relationships between the catalogued exhibition projects by tags and keywords.

\section{Conclusion}

The project of the visual interactive tool, currently under development, introduces a free access open system for verifying and enhancing the state of the research. The parameters chosen for cataloguing, which also refer to commonly used language, make the system accessible to a wide range of users.

The integration of data visualization tools into knowledge-building processes is becoming an increasingly relevant project theme, to which designers can give contribute by studying and developing new adaptive interfaces.

The most interesting challenge for the future could be to collaborate with colleagues to implement the system creating new instances and narrations for the contents, even using machine learning to analyse connections and sources. 


\section{References}

1. Dalla Mura, M. (2016, March). Storia digitale e design / 4 - Il digitale come archivio. Retrieved from: http://www.maddamura.eu/blog/language/it/design-e-storia-digitale4-il-digitale-come-archivio/

2. Manovich, L. (2009). Cultural Analytics: Visualising Cultural Patterns in the Era of «More Media». Domus, (Milan), March.

3. Manovich, L. (2012). Media Visualization: Visual Techniques for Exploring Large Media Collections. (K. Gates, A C. Di) (Vol. Media Studies Futures). Malven. MA: Blackwell.

4. Hochman, N., \& Manovich, L. (2013). Zooming into an Instagram City: Reading the local through social media. First Monday, 18(7). https://doi.org/10.5210/fm.v18i7.4711

5. Hochman, N., \& Schwartz, R. (2012). Visualizing Instagram: Tracing cultural visual rhythms (pagg. 6-9). Presented at Proceedings of the Workshop on Social Media Visualization (SocMedVis) in conjunction with the Sixth International AAAI Conference on Weblogs and Social Media (ICWSM-12).

\section{Projects and related references}

6. Santiago Ortiz - http://intuitionanalytics.com/other/lostalgic/

7. Santiago Ortiz - http://moebio.com/newk/twitter/

8. Ortiz, S. (2014, June, 13). Six Months. Eyeo Festival 2014 [Video file]. Retrieved from: https://vimeo.com/113312415

9. Mediarchitecture, - http://mediaarchitecture.de/projekte/impuls_bauhaus-interaktivertisch-interactive-table/

10. Max Planck Institutes - http://max-planck-research-networks.net/

11. Weber, J., Wolter, A., (2015). Interaktive Visualisierungen als Erkenntnismodelle am Beispiel des Projekts «ImpulsBauhaus». Geschichte und Informatik, volume (18/19), 285308. Retrieved from http://blog.ahc-ch.ch/wp-content/uploads/2015/09/12-WeberWolter.pdf

12. Elsevier's Scopus Data Drives Visualization of International Collaborative Research Networks for new Max Planck Science Gallery. (2011, September). Retrieved from: https://www.elsevier.com/about/press-releases/science-and-technology/elseviersscopus-data-drives-visualization-of-international-collaborative-research-networks-fornew-max-planck-science-gallery

13. The MIT Senseable City Lab - http://senseable.mit.edu/bbva/

14. Piovano, L., Andréu, A., Galloso, I., Feijó, C. (2015). A perceptive insight into cities patterns by visualizing urban economies. Presented at Proceedings of the International Conference on Information Visualization Theory and Applications (IVAPP) in 2014.

15. The New York Times http://www.nytimes.com/interactive/2008/02/23/movies/20080223_ REVENUE_GRAPHIC.html

16. Havre, S., Hetzler, B., Nowell, L. (1999). ThemeRiver ${ }^{\text {TM}: ~ I n ~ S e a r c h ~ o f ~ T r e n d s, ~ P a t t e r n s, ~ a n d ~}$ Relationships. In Proceedings of IEEE Symposium on Information Visualization, InfoVis '99, October 25-26, San Francisco CA.

17. Kirk, A. (2010, August). Making sense of streamgraphs. Retrieved from: http://www.visualisingdata.com/2010/08/making-sense-of-streamgraphs/

18. A.A.V.V. - http://www.evolutionoftheweb.com/ 
19. Newman, W.E. (2017). Data Visualization for Design Thinking: Applied Mapping. New York, USA: Routledge Taylor \& Francis

20. Google Research - https://research.google.com/bigpicture/music/

21. Cichowlas, A., Lam, T. (2014, January). Explore the history of Pop -- and Punk, Jazz, and Folk -- with the Music Timeline. Retrieved from: https://research.googleblog.com/2014/01/explore-history-of-pop-and-punk-jazz.html

22. The Museum of Modern Art https://www.moma.org/interactives/exhibitions/2008/elasticmind/

23. Antonelli, P. (2016). Design and the Elastic Mind. New York, USA: The Museum of Modern Art

24. Google Art \& Culture https://artsexperiments.withgoogle.com/tags/detail/\#Figure_drawing

25. Sood, A., Diagne, C. (Eds.). (17 $7^{\text {th }}$ February 2016). Every piece of art you've ever wanted to see - up close and searchable. Vancouver, Canada: TED Conferences, LLC

26. The MIT Senseable City Lab - http://senseable.mit.edu/healthinfoscape/

27. Chen, X. (2011, July). Health InfoScape. Retrieved from: http://xiaojichen.com/2011/health-infoscape/

28. The New York Times http://www.nytimes.com//interactive/2009/07/31/business/20080801-metricsgraphic.html?hp 